\title{
Gain Flatness and Noise Figure Optimization of C-Band EDFA in 16-channels WDM System using FBG and GFF
}

\author{
Chakkour Mounia ${ }^{1}$, Aghzout Otman ${ }^{2}$, Ait Ahmed Badiaa ${ }^{3}$, Chaoui Fahd ${ }^{4}$, \\ Alejos Ana Vazquez ${ }^{5}$, El Yakhloufi Mounir ${ }^{6}$ \\ ${ }^{1,3,4}$ Department of Physics, Faculty of Sciences, Abdelmalek Esaadi University, Tetouan, Morocco, \\ ${ }^{2}$ Electronics \& Microwave Group, Telecommunication Department, ENSA, Tetouan, Morocco \\ ${ }^{5}$ Department of Teoría de la Señal y Comunicación, University of Vigo, Pontevedra, Vigo, Spain \\ ${ }^{6}$ Condensed Matter Physics Group, Faculty of Sciences, Abdelmalek Esaadi University, Tetouan, Morocco
}

\begin{tabular}{|c|c|}
\hline Article Info & ABSTRACT \\
\hline Article history: & In this paper, Gain Flatness and Noise Figure of Erbium Doped Fiber \\
\hline & Amplifier (EDFA) have been investigated in 16-channels Wavelength \\
\hline Received Sep 29, 2016 & Division Multiplexing (WDM). Fiber Bragg Grating (FBG) is used in C-band \\
\hline Revised Nov 10, 2016 & with the aim to achieve flat EDFA output gain. The proposed model has been \\
\hline Accepted Nov 25, 2016 & $\begin{array}{l}\text { studied in detail to evaluate and to enhance the performance of the } \\
\text { transmission system in terms of gain, noise figure and eye diagram of the }\end{array}$ \\
\hline Keyword: & $\begin{array}{l}\text { received signals. To that end, various design parameters have been } \\
\text { investigated and optimized, such as frequency spacing, EDF length and }\end{array}$ \\
\hline EDFA & temperature. To enhance the transmission system performance in terms of \\
\hline FBG & $\begin{array}{l}\text { gain flatness, the Gain Flattening Filter (GFF) has been introduced in the } \\
\text { design. To prove the efficiency of the new design, the optical transmission }\end{array}$ \\
\hline GFF & system with optimized design parameters has been compared with a previous \\
\hline WDM & $\begin{array}{l}\text { works in the literature. The simulation results show satisfactory performance } \\
\text { with quasi-equalized gain for each channel of the WDM transmission system. }\end{array}$ \\
\hline
\end{tabular}

Copyright $(2016$ Institute of Advanced Engineering and Science. All rights reserved.

\section{Corresponding Author:}

Chakkour Mounia,

Departement of Physics, Faculty of Sciences,

Abdelmalek Esaadi University,

Faculty of Tetouan, BP. 2121 Me Hannech II, 93030 Tetouan Morocco.

Email: chakkourm@gmail.com

\section{INTRODUCTION}

In the last decade, remarkable contributions have been made by researchers in using Erbium Doped Fibers Amplifiers (EDFA) for conventional C band optical communication (1530nm- 1565nm), since EDFAs offer high capacity, long-lifespan and multiple connection of optical communication network applications [12]. EDFAs also are designed to lessen the effects of dispersion and attenuation, which allows improved performance for long-haul optical systems [3]. However, the use of EDFA in WDM transmission systems and their related optical networks generates uneven output gain between optical channels [4], [5]. In long amplifier chains, even small spectral gain variations can give rise to large differences in the received signal power, causing large BER discrepancies between received signals [6]. For some optical channels, complete power extinction can occur at the system output, due to insufficient gain offset along the amplifier chain [7], [8]. The purpose of this paper is to treat this problem, caused by EDF Amplifiers in complexed WDM systems, by using Fiber Bragg Gratings (FBG) and Gain Flattening Filter (GFF). GFF are typically used to flatten and smooth out unequal signal intensities over a specified wavelength range [9]. GFF is used in conjunction with FBG to overcome the nonlinear effects generated by the use of EDFA in WDM systems and then to ensure that all the amplified channels have the same gain output [10], [11]. The paper is organized as follow, on one hand, we present the proposed model using FBG in sixteen channel wavelength 
division multiplexing system for C-Band frequencies. The developed method will be modeled and simulated to assess and to improve the transmission system performance in terms of EDF gain, gain flatness, noise figure and eye diagram of the received signals. For this purpose, various design parameters which include frequency spacing, EDF length and temperature have been investigated in order to optimize all settings. The optical transmission system under study with optimized design parameters has been compared with a previous model to prove the efficiency of the proposed method. On the other hand, the Gain flattening Filter (GFF) has been added to enhance the reliability of the whole model. To prove the efficiency of our design, the optical transmission system has been applied and compared with previous work proposed in the literature [12], [13]. All results are analyzed using Opti System simulator. The simulation results prove the high reliability of the developed gain flattening method.

\section{WDM-EDFA SYSTEM USING UNIFORM FBG}

\subsection{System Design}

In first part, we present a detailed study of the proposed model using Ideal FBG in C-Band frequency of sixteen channel wavelength division multiplexing system. As shown in Figure 1 the transmission system under study consists of 16 input signals (channels), an ideal multiplexer, two isolators, a pump laser, erbium doped fiber, demultiplexer, photo detector PIN, low pass Bessel filter, 3R regenerator and BER analyzer. The input of the system is 16 wavelength multiplexed signals with wavelengths varies from $1546 \mathrm{~nm}$ to $1558 \mathrm{~nm}$. The pumping at $980 \mathrm{~nm}$ is used to excite the erbium doped fiber atoms to a higher energy level. EDFA is combined with a dispersion compensator to overcome chromatic dispersion effects. Chromatic dispersion occurs when different wavelengths of light pulses are launched into the optical fiber. These pulses travel at different speeds due to the variation of refractive index exciting the erbium doped fiber atoms to a higher energy level. The optical fiber used is single mode fiber because it has higher data rate and long distance transmission. The fiber Bragg grating and the Photodetector Diode Positive Intrinsic Negative (PIN) are used as the dispersion compensator and optical signal translator respectively. For the operating optical transmission system, different parameters are adequately chosen, such as, Input power $-25 \mathrm{~dB}$, reference wavelength $1550 \mathrm{~nm}$, fiber length $50 \mathrm{~km}$, and attenuation coefficient of cable $0.2 \mathrm{~dB} / \mathrm{km}$. To achieve a high gain the frequency spacing, pump power, EDF length, and Temperature are considered as critical parameters for the study.

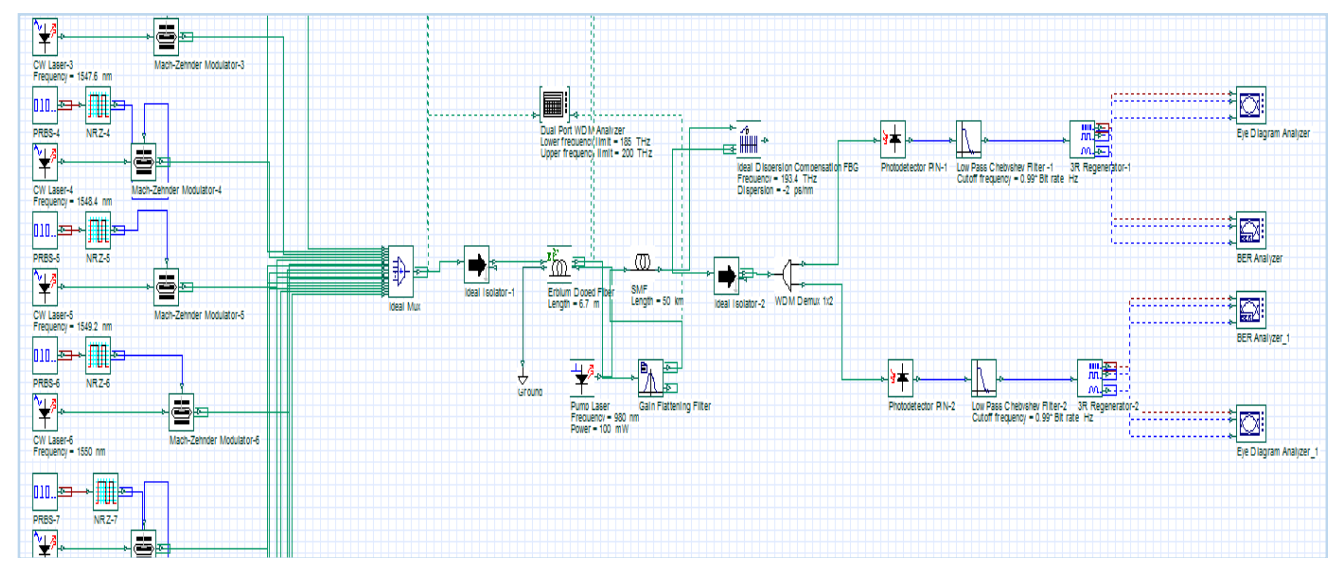

Figure 1. 16 channels WDM-EDFA system using FBG

\section{DESIGN AND PERFORMANCE OPTIMIZATION OF WDM SYSTEM}

\subsection{Signal Quality for Different Frequency Spacing's}

Frequency spacing is the spacing between two wavelengths or frequencies in a WDM system. It can be measured in units of wavelengths or frequencies. Four-wave mixing effect is critically dependent on the channel spacing and fiber chromatic dispersion. Decreasing the channel spacing increases the four-wave mixing effect, and so does decrease the chromatic dispersion effects. In general, scattering effects are characterized by a gain coefficient, measured in meters per watt. The gain coefficient is a measure of the strength of the nonlinear effect. The gain of different channel has to be equalized for identical performance of all the channels. 
$0.2 \mathrm{~nm}$

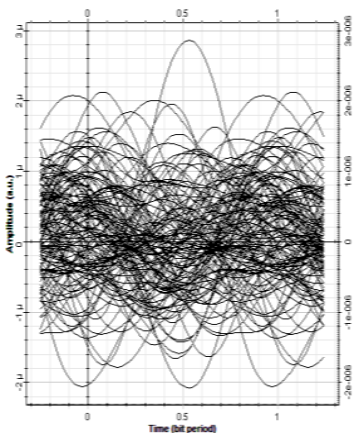

$0.4 \mathrm{~nm}$

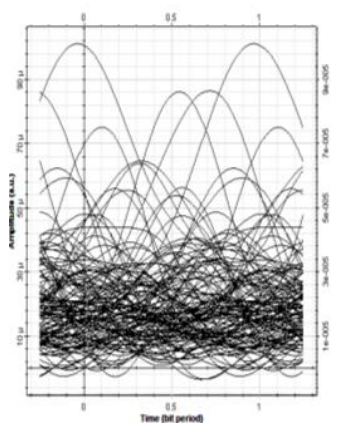

$0.6 \mathrm{~nm}$

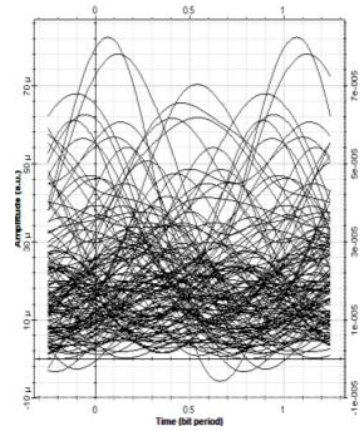

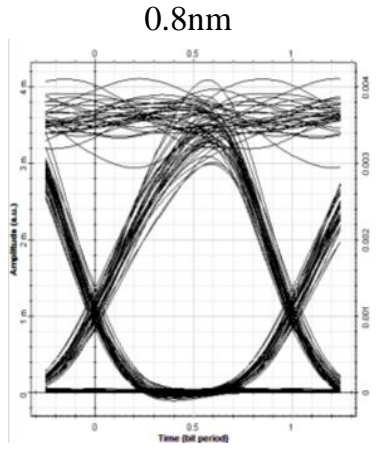

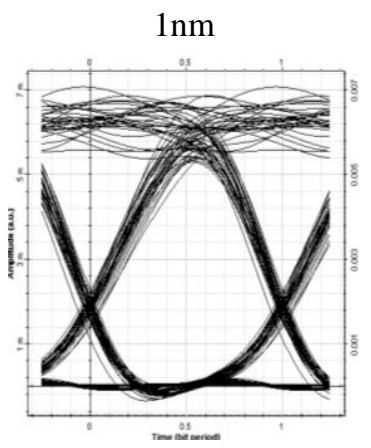

Figure 2. Eye Diagrams at different values of Frequency Spacing

Figure 2 shows the effect of nonlinearities on the eye diagrams of the received signals. By comparing the 5 eye diagrams, it can be seen that the eye opening is higher and the signal quality is better in $0.8 \mathrm{~nm}$ and $1 \mathrm{~nm}$.

\subsection{Gain and Noise Figure for Different EDF Lengths}

Erbium Doped Fiber length impact on the performance of proposed system is also studied. The length of the EDF depends upon the input signal power, Er+3 ion density and the signal and pump wavelength. In Figure 3, we present the variation of gain and noise figure for different EDF length. It is clear that for $4 \mathrm{~m}$ and $5 \mathrm{~m}$ the gain are low and noise figure are high, by against, for $10 \mathrm{~m}$ the Noise figure is high. For $6.7 \mathrm{~m}$ and $7.1 \mathrm{~m}$, the gain is almost the same, however for a length of $6.7 \mathrm{~m}$ the Noise figure is low, which means that $6.7 \mathrm{~m}$ is the most proper EDF length.
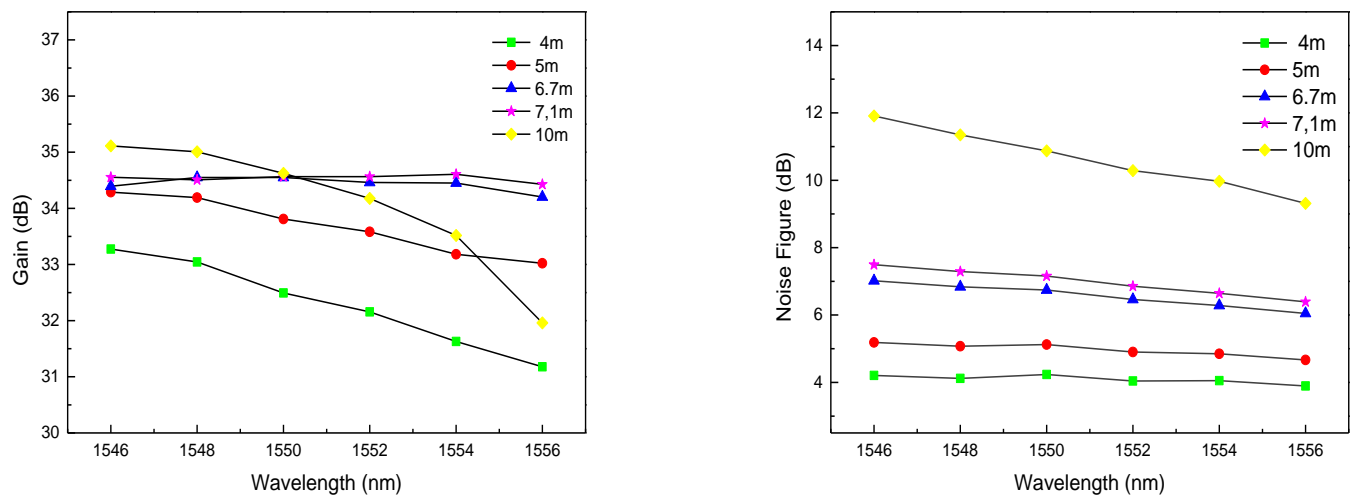

Figure 3. Variation of Gain and Noise Figure at different values of EDF length 


\subsection{Gain and Noise Figure for Different Temperature Values}

In this section we present the effect of temperature on gain and noise figure respectively. From Table 1 and Table 2 we can observe that $10^{\circ} \mathrm{C}$ and $20^{\circ} \mathrm{C}$ have achieved the best Gain Output, and $20^{\circ} \mathrm{C}$ and $50^{\circ} \mathrm{C}$ have obtained the lowest Noise Figure. So we can conclude that $20^{\circ} \mathrm{C}$ leads to the best optimized performance based on Gain and Noise Figure.

Table 1. Variation of gain with respect to channel wavelength at different values of temperature

\begin{tabular}{ccccc}
\hline $\begin{array}{c}\text { Wavelength } \\
(\mathrm{nm})\end{array}$ & \multicolumn{3}{c}{ Gain $(\mathrm{dB})$ at Temperature $(\mathrm{C})$} \\
\hline 1546 & 34,430 & 34,572 & 34,393 & 34.267 \\
1548 & 34,667 & 34,637 & 34,549 & 34.352 \\
1550 & 34,698 & 34,647 & 34,546 & 34.266 \\
1552 & 34.629 & 34.572 & 34,461 & 34.173 \\
1554 & 34.641 & 34.576 & 34,451 & 34.133 \\
1556 & 34.392 & 34.326 & 34,201 & 33.895 \\
\hline
\end{tabular}

Table 2. Variation of noise figure with respect to channel wavelength at different values of temperature

\begin{tabular}{ccccc}
\hline $\begin{array}{c}\text { Wavelength } \\
(\mathrm{nm})\end{array}$ & $5^{\circ} \mathrm{C}$ & $10^{\circ} \mathrm{C}$ & $20^{\circ} \mathrm{C}$ & $50^{\circ} \mathrm{C}$ \\
\hline 1546 & 7.359 & 7.239 & 7.016 & 6.453 \\
1548 & 7.154 & 7.042 & 6.836 & 6.308 \\
1550 & 7.054 & 6.933 & 6.742 & 6.078 \\
1552 & 6.717 & 6.628 & 6.461 & 6.024 \\
1554 & 6.510 & 6.431 & 6.284 & 5.893 \\
1556 & 6.249 & 6.180 & 6.048 & 5.842 \\
\hline
\end{tabular}

Figure 4 represents the behavior of the gain at different values of temperature in the wavelength of our interest. It can be observed for $1548 \mathrm{~nm}$ that when the temperature increases the gain value remains almost the same, which means that the gain flatness versus temperature can be considered as an added value for our work, since in a previous work, the gain at $1548 \mathrm{~nm}$ decreases as temperature increases [9].

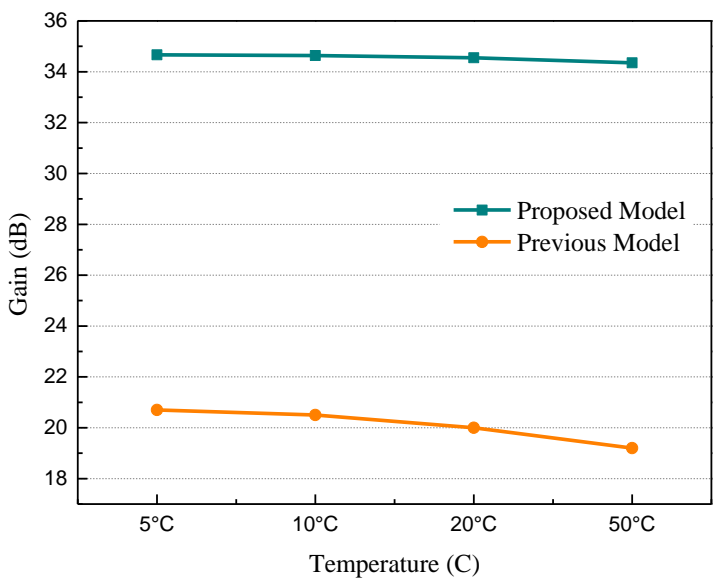

Figure 4. Gain variation for $1548 \mathrm{~nm}$ wavelength at different values of temperature

\subsection{System Comparison}

The proposed model under study with optimized values of FS, EDF length and Temperature at different pump powers has been compared with a previous model proposed by other authors [12]. Firstly, the eye diagrams at data receivers of both models have been introduced using the same initial setting as shown in Figure 5 . 


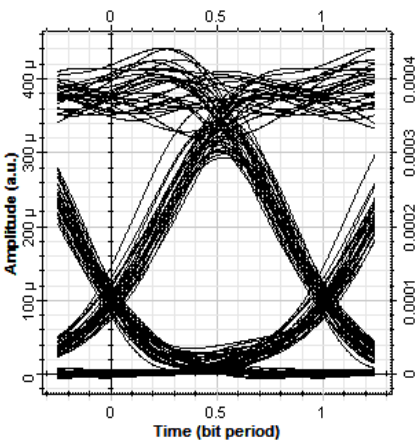

(a)

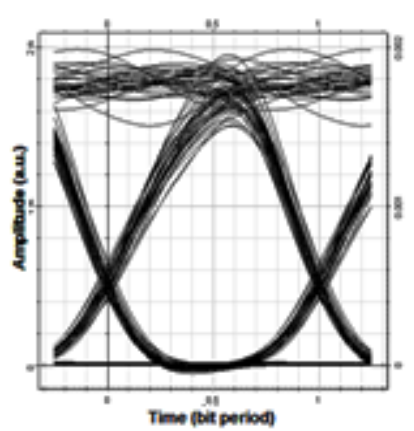

(b)

Figure 5. Eye diagram of the received signals, a: previous model [12], b: developed model.

By comparing the 2 eye diagrams, it is clear that the eye opening is higher and the signal quality is better. The comparison has then been carried out based on Gain and Noise Figure at different pump powers as shown in Table 3 and Table 4.

Table 3. Gain with different Channel Wavelength

\begin{tabular}{ccccccccc}
\hline \multicolumn{1}{c}{} & \multicolumn{7}{c}{ Gain (dB) at pump power } \\
Wavelength (nm) & \multicolumn{2}{c}{100} & \multicolumn{2}{c}{200} & \multicolumn{2}{c}{300} & \multicolumn{2}{c}{400} \\
& {$[12]$} & Our model & {$[12]$} & Our model & {$[12]$} & Our model & {$[12]$} & Our model \\
\hline 1546 & 33.474 & 34.393 & 36.917 & 37.661 & 38.371 & 39.402 & 39.945 & 40.584 \\
1548 & 33.167 & 34.549 & 36.736 & 37.683 & 38.607 & 39.440 & 39.876 & 40.591 \\
1550 & 33.036 & 34.546 & 36.675 & 37.590 & 38.578 & 39.211 & 39.867 & 40.312 \\
1552 & 33.092 & 34.461 & 36.860 & 37.372 & 38.828 & 38.923 & 40.157 & 40.205 \\
1554 & 33.344 & 34.451 & 36.177 & 37.283 & 39.168 & 38.792 & 40.507 & 40.535 \\
1556 & 32.786 & 34.201 & 35.788 & 36.906 & 38.829 & 39.196 & 39.990 & 40.111 \\
\hline
\end{tabular}

Table 4. Noise Figure with different Channel Wavelength

\begin{tabular}{ccccccccc}
\hline \multirow{2}{*}{ Wavelength (nm) } & \multicolumn{2}{c}{100} & \multicolumn{3}{c}{ Noise Figure (dB) at pump power } & \multicolumn{2}{c}{400} \\
& {$[12]$} & Our model & {$[12]$} & Our model & {$[12]$} & Our model & {$[12]$} & Our model \\
\hline 1546 & 12.806 & 7.016 & 10.768 & 6,616 & 10.030 & 6.479 & 9.630 & 6.403 \\
1548 & 12.314 & 6.836 & 10.350 & 6.450 & 9.646 & 6.314 & 9.269 & 6.237 \\
1550 & 11.749 & 6.742 & 9.883 & 6.404 & 9.224 & 6.291 & 8.875 & 6.228 \\
1552 & 11.099 & 6.461 & 9.355 & 6.126 & 8.875 & 6.008 & 8.430 & 5.940 \\
1554 & 10.543 & 6.284 & 8.960 & 5.981 & 8.425 & 5.878 & 8.145 & 5.820 \\
1556 & 9.884 & 6.048 & 8.482 & 5.750 & 8.019 & 5.643 & 7.797 & 5.582 \\
\hline
\end{tabular}

The obtained gain in the previous work at pump power of $100 \mathrm{~mW}$ is $33.474 \mathrm{~dB}$ with noise figure of $12.806 \mathrm{~dB}$. While the gain of the model developed in this work at same pump power of $100 \mathrm{~mW}$ is $34.393 \mathrm{~dB}$ with noise figure of $7.016 \mathrm{~dB}$, which means that a better gain power \& less Noise Figure have been achieved. The simulation results demonstrate the high reliability of the proposed model in comparison with other models.

\section{EDFA-WDM SYSTEM USING UNIFORM FBG AND GFF}

\subsection{Proposed Model with GFF}

To enhance more and more the reliability of the new model, we introduce the Gain flattening Filter (GFF) in our system as can be shown in Figure 6. The GFF is placed after the FBG before the demultiplexing process, so the multiplexed signals can be filtered automatically from unequal gain values. 


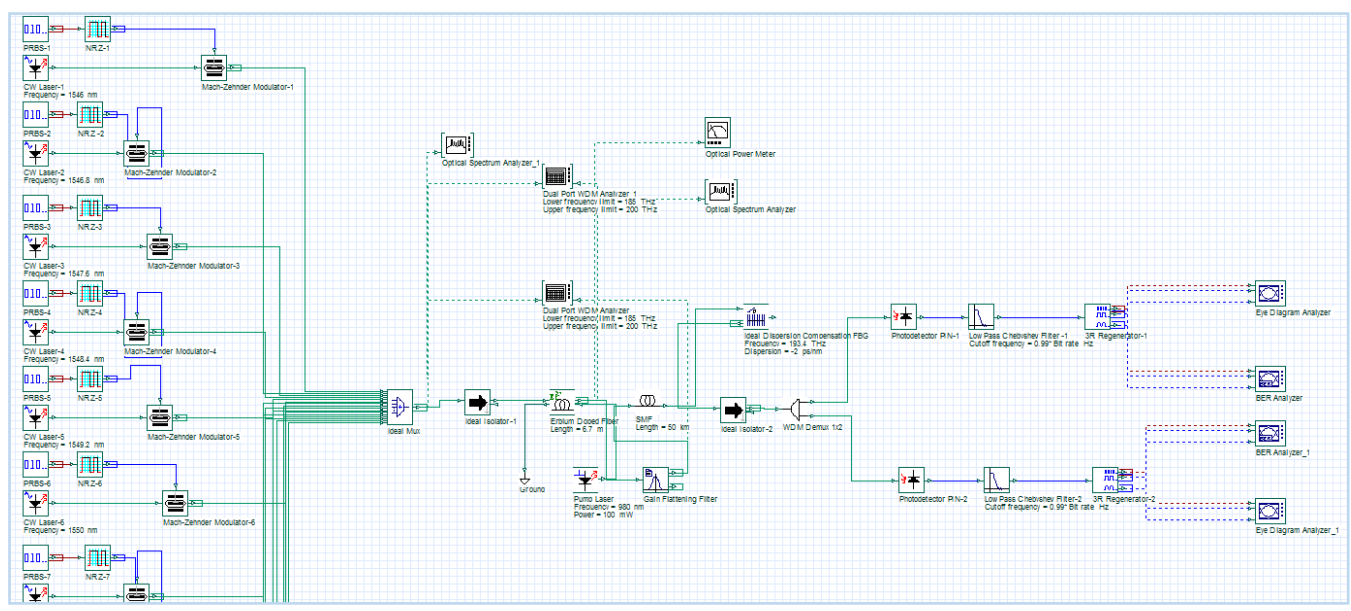

Figure 6. 16 channels WDM-EDFA system using FBG and GFF

\subsection{Performance Analysis}

The gain flatness of the developed model with and without GFF is analyzed for different frequency spacing's. Table 5 shows that, the Gain flatness has increased by the use of GFF, especially for the optimized value of frequency spacing $0.8 \mathrm{~nm}$, which went down from $0.647 \mathrm{~dB}$ to $0.303 \mathrm{~dB}$.

Table 5. Gain flatness at different values of frequency spacing

\begin{tabular}{ccc}
\hline Frequency spacing $(\mathrm{nm})$ & $\begin{array}{c}\text { Gain Flatness (dB) Without } \\
\text { GFF }\end{array}$ & Gain Flatness (dB) With GFF \\
\hline 0,2 & 0.254 & 0.153 \\
0,4 & 0.207 & 0.202 \\
0,6 & 0.261 & 0.242 \\
0,8 & 0.647 & 0.303 \\
1 & 2.281 & 1.555 \\
\hline
\end{tabular}

Figure 7 shows the gain flatness of the developed model with GFF and without GFF based on different EDF lengths. Results prove that with GFF we obtain better Gain flatness as compared to the developed model without GFF. It can also be noticed that $6.7 \mathrm{~m}$ is the most proper EDF length since we obtain a minimum value of gain flatness $0.303 \mathrm{~dB}$.

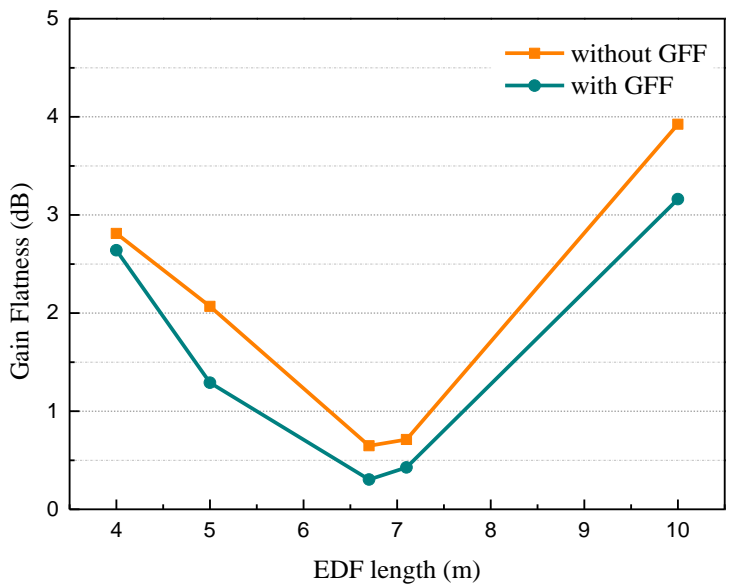

Figure 7. Variation of Gain Flatness at different values of EDF length

The Gain Flatness of the proposed method with and without GFF for different Temperature values is depicted in Figure 8. It can be seen that the use of GFF offers better Gain Flatness for all temperature values. 


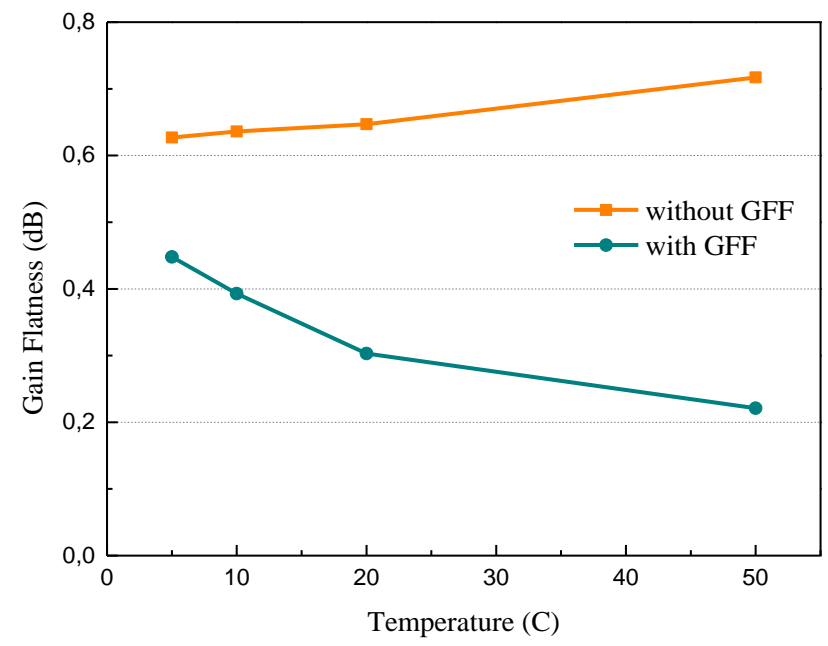

Figure 8. Variation of Gain Flatness at different Temperature values

Table 6 shows the comparison results of Gain Flatness based on pump power for the proposed method with GFF and without GFF. One can see that the proposed model with GFF has provided the lowest gain flatness which results in all over better performance.

Table 6. Gain flatness with different pump power

\begin{tabular}{ccc}
\hline Pump Power $(\mathrm{mW})$ & Gain Flatness (dB) Without & Gain Flatness (dB) With \\
& GFF & GFF \\
\hline 100 & 0.647 & 0.303 \\
200 & 1.221 & 0.361 \\
300 & 1.547 & 0.692 \\
400 & 1.768 & 0.768 \\
\hline
\end{tabular}

\section{PERFORMANCE COMPARISON}

In this part, we compare the proposed method performance to prove the efficiency of our method. So we have applied the proposed method with EDF and GFF in the same communication system [13], using the same initial setting: $20^{\circ} \mathrm{C}$ temperature, $7 \mathrm{~m}$ fiber length and the signal wavelength of $1546.8 \mathrm{~nm}$ as shown in Figure 9.

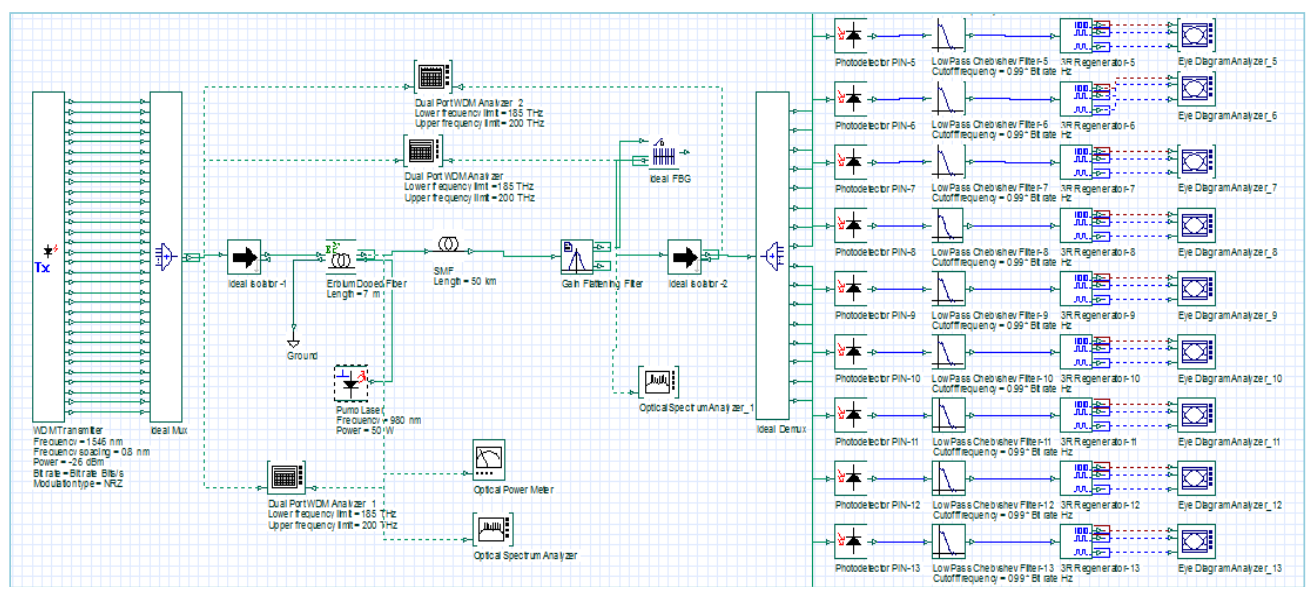

Figure 9. The design system of EDFA in WDM system 
Table 7 shows the comparison results in terms of gain and the gain flatness. It can be clearly seen that better gain value and improved gain flatness have achieved.

Table 7. Comparison parameters with a previous model and our model

\begin{tabular}{cccc}
\hline \multirow{2}{*}{ Parameters } & \multirow{2}{*}{ Previous Model } & Without GFF & With GFF \\
\hline Gain & & 36.28 & 37.12 \\
Gain Flatness & 28 & 0.85 & 0.10 \\
\hline
\end{tabular}

\section{CONCLUSION}

In this paper, the Gain Flatness and the Noise Figure of EDF Amplifier in 16-channels WDM system have been studied. The gain non-uniformity for each channel using FBG and GFF has been corrected in order to equalize the amplitude gain in the WDM system. The most convenient design parameters are optimized to be used in the new method. Useful results show that $0.8 \mathrm{~nm}, 6.7 \mathrm{~m}$ and $20^{\circ} \mathrm{C}$ are the most proper values of Frequency spacing, EDF length and Temperature respectively. Results have been compared with previous works in terms of the output Gain and Noise Figure. The simulation results prove that the proposed method offers improved values of performance all parameters.

\section{REFERENCES}

[1] R. Ramaswami, K.N. Sivarajan, G.H. Sasaki, "Optical Networks: A Practical Perspective", Third Edition. ELSEVIER, 2010.

[2] B.R Mhdi*, N. Aljaber, S.M. Aljwas, A.H., "Khalid, Design and Construction of Optical Fiber Sensor System for Detection of the Stress and Fine Motion", International Journal of Nano Devices, Sensors and Systems (IJ-Nano), Volume 1, No. 1, May 2012.

[3] P. Shukla, K. Kaur, "Performance Analysis of EDFA for Different Pumping Configurations at High Data Rate", Global Journal of Researches in Engineering Electrical and Electronics Engineering, Volume 13 Issue 9 Version $1.0,2013$.

[4] M. Chakkour, A. Hajaji and O. Aghzout, "Design and Study of EDFA-WDM Optical Transmission System using FBG at 10 Gbits/s Chromatic Dispersion Compensation Effects", Mediterranean Conference on Information \& Communication technologies, May 2015.

[5] M.M. Ismail, M.A. Othman, "EDFA-WDM Optical Network Design System", International Journal for Light and Electron Optics, optic (Elsevier), vol. 53,pp. 294-302,2013.

[6] B. Rindhe, J. Digge, S. Narayankhedkar, "Implementation of Optical OFDM Based System for Optical Networks". International Journal of Electrical and Computer Engineering (IJECE), Vol. 4, No. 5, October 2014.

[7] R. Kaler and R S Kaler, "Gain and Noise Figure Performance of ErbiumDoped Fiber Amplifiers (EDFA) and Compact EDFAs", pp. 440-443, Elsevier.2011.

[8] J. Usman Sindhi, Rohit B Patel, injal A Mehta and Vivekananda Mishra, "performance analysis of 32-channel WDM system using erbium doped fiber amplifier", International Journal of Electrical and Electronic Engineering \& Telecommunications, Vol. 2, No. 2, April 2013.

[9] R. Anthony, S. Biswas "Temperature Dependent Gain Analysis of a Cascaded C-Band EDFA DWDM Network". International Journal for Light and Electron Optics, optic (Elsevier), Procedia Technology, 2012

[10] F.Chaoui, A. Hajaji, O. Aghzout, M. Chakkour, M. El Yakhloufi,"Chirped Bragg Grating Dispersion Compensation in Dense Wavelength Division Multiplexing Optical Long-Haul Networks", International Journal of Microwave and Optical Technology (IJMOT), Volume. 10, No. 5, September 2015.

[11] B. ALTINER, N. Özlem ÜNVERDİ, "Modelling - Simulation and Gain Flattening Improvements for an Erbium Doped FiberAmplifier", IEEE, 2009.

[12] K Kaur, K. Singh, "Performance analysis of 16-channel WDM system using Erbium Doped Fiber Amplifier", International Journal of Engineering and Innovative Technology (IJEIT), Volume 3, Issue 6, December 2013.

[13] A.H.M. Huseina, F.I. El-Nahal, "Optimizing the EDFA gain for WDM lightwave system with temperature dependency", International Journal for Light and Electron Optics, optic (Elsevier), Procedia Technology, 2011. 


\section{BIOGRAPHIES OF AUTHORS}
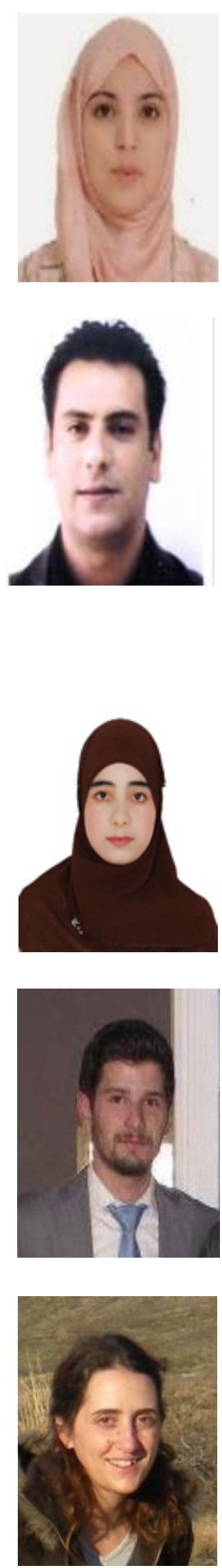

Mounia Chakkour was born in Tetouan, Morroco. She received the Engineer Degree in Mecatronicsat the National School of Applied Sciences from Abdelmalek Essaadi University, Tetouan, Morocco in 2013. She iscurrently working toward the Ph.D. degree in Telecommunications Engineering with the Telecommunication Department at the National School of Applied Sciences, Abdelmalek Essaâdi University. Hermain research interests Optical communications, optical sensor networks, and Fiber Bragg Grating Technology.

Otman Aghzoutwas born in Tétouan, Morocco. He received the Electronics degree from Abdelmalek Essaadi University, Tétouan, Morocco, in 1995, M. and Ph.D. degrees in Telecommunications Engineering at the High School of Telecommunications Engineering (ETSITGC) of Canary University, Spain in 2000 and January 2002, respectively. He has also been a Researcher Student at the Microwave Group of the Dept. of Electronics and Electromagnetism, University of Seville (Seville, Spain) from 1996 till 1999. In January 2002, he joined the Medical Technology Center (CTM) of the University Hospital of GC, where he worked in Medical Engineering applications for two years. (2002-2004) has been a Teacher Assistant on Telecommunications Engineering and Postdoctoral Researcher at the Department of the Signal Processing Engineering, High School of TE (ETSITGC). From 2009 until @)!6he joined the Dept. Of Engineering Technologies: Telecommunications and Mecatronics (TITM) as an Associate Professor of Telecommunications Engineering, National School of applied Sciences, UAE, Tétouan, Morocco. Currently he is interested on printed microwave passive and active circuits, filters and antenna designs.

Badiaa Ait Ahmed was born in Chefchaouen, Morroco. He received the Engineer Degree in telecommunication engineering at the National School of Applied Sciences from Abdelmalek Essaadi University, Tetouan, Morocco 2014. She is currently working toward the Ph.D. degree in Telecommunications Engineering with Advanced Sciences\& Technology Group, Telecommunication Department, ENSA, Tetouan, at Abdelmalek Essaadi University, Morocco. Her research interests Metamaterial filters design and UWB antenna.

Fahd Chaoui received the State Engineer Degree in Mechatronics from the National School of Applied Sciences, Abdelmalek Essaâdi University, Tétouan, Morocco, in 2013. He is currently working toward the Ph.D degree with the Telecommunication Department at the National School of Applied Sciences, Abdelmalek Essaâdi University. His main research interests Optical communications, optical sensor networks, and Fiber Bragg Grating Technology.

Ana Vazquez Alejos has beenworking with the Department of Signal Theory and Communications, University of Vigo, as Research and Teaching staff. She completed her $\mathrm{Ph}$.D. thesis on the radio channel characterization for the millimeterwave frequencies. In 2009 she wasgranted with the arie Curie International Outgoing Fellowship, carrying out the outgoing phase in the New Mexico State University (NM, USA), with a research focused on propagation through dispersive media, andradar waveform generation. In 2002, her M.S. thesisreceived the Ericcson Award by the Spanish Association of Electrical Engineers, as the best Multimedia Wireless Project. Her research work includes radio propagation, communication electronics, wideband radio channel modeling, multimedia wireless systems, waveform andnoise code design, and radar.Alejos is a Reviewer for several IEEE and IET journals, and works for the IEEE TMC Spain Chapter. 


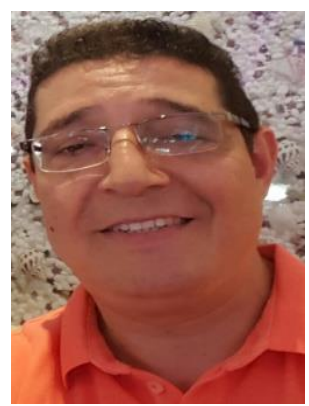

Mounir H. El Yakhloufi was born in Tetouan, Morocco. He obtained the DEUG in Mathematics-Physics (MP) in 1987 and Physics degree option Materials Science in 1989 at the University Allal Ben Abdelah, Fes, Morocco. He continued his studies in France at the University of Saint Jerome, Marsseille. He had his DEA option material sciences in 1990 and he prepared his doctorate at Microscopy and Diffraction Laboratory Electronics at the University of St. Jerome that he sustained in 1993. He had a doctoral post at the University of StJérôme for two years. He was hired as professor assistant at Abdel Malek Essaaidi University in 1996, Tetouan, Morocco. He prepared another PhD state that he sustained at 2002. He is now Professor of Higher Education at the Faculty of Science of Tétouan. 